2005-01-01

\title{
Structural Property Relationships in Conjugated Polymers
}

\author{
Patrick Lynch \\ Technological University Dublin, patrick.lynch@tudublin.ie \\ Luke O'Neill \\ Technological University Dublin, Luke.oneill@tudublin.ie \\ J. Whelan \\ Technological University Dublin
}

See next page for additional authors

Follow this and additional works at: https://arrow.tudublin.ie/nanolart

Part of the Physics Commons

\section{Recommended Citation}

Lynch, P., O'Neill, L. \& Whelan, J. (2005). Structural property relationships in conjugated polymers.

Proceedings of Optolreland 2005,SPIE, vol. 5826, pg. 242. doi:10.1117/12.598779

This Article is brought to you for free and open access by the NanoLab at ARROW@TU Dublin. It has been accepted for inclusion in Articles by an authorized administrator of ARROW@TU Dublin. For more information, please contact arrow.admin@tudublin.ie, aisling.coyne@tudublin.ie,gerard.connolly@tudublin.ie.

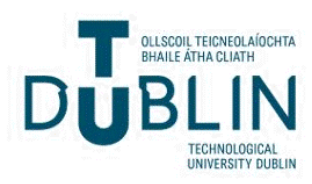




\section{Authors}

Patrick Lynch, Luke O'Neill, J. Whelan, Mary McNamara, and Hugh Byrne 


\title{
Structural property relationships in conjugated polymers
}

\author{
P. Lynch*ac L. O’Neill ${ }^{\text {bc }}$ J. Whelan ${ }^{\text {a M. McNamara }}{ }^{\text {ac }}$ H. J. Byrne ${ }^{c}$ \\ ${ }^{a}$ School of Chemistry, Dublin Institute of Technology, Kevin St., Dublin 8, Ireland \\ ${ }^{\mathrm{b}}$ School of Physics, Dublin Institute of Technology Kevin St., Dublin 8, Ireland \\ ${ }^{\mathrm{c}}$ Focas Institute, Dublin Institute of Technology Kevin St., Dublin 8, Ireland
}

\begin{abstract}
The synthesis of a series of PPV derivative polymers by the Wittig-Horner reaction is described. The structure of each polymer is varied and the effects of these variations on the optical properties is explored. The effects of alkyloxy side chains is observed between the PPV derivatives Poly(-p-phenylvinylene-co-2,5-bis-octyloxy phenylvinylene.) PPV-OPV and Poly (para-2,5-bis-(n-octyloxy)phenylvinylene) POPV. The phenyl units of the soluble PPV derivative POPV are replaced by alternate naphthyl units in the polymer Poly(2,5-bis(n-octyloxy)-1,4-phenylene vinylene-1,5-bis(n-octyloxy)-2,6-naphthylene vinylene) POPN-ONV and then fully by naphthyl units in Poly(2,6-bis-(n-octyloxy)-1,5-NaphthyleneVinylene) PONV. The addition of alkyloxy sidechains served to red shift the fluorescence emission as expected. The systematic conversion of phenyl to naphthyl units blue shifted the emission considerably while reducing the Stokes shift. There is evidence to suggest some localization of the $\pi$ electrons over the aromatic units of the polymer backbone. PONV is shown to have greater stability towards photo-oxidation then either POPV or PPV-OPV.
\end{abstract}

Keywords: Poly para phenylvenylene derivatives, Optical absorbance and emission spectroscopy, Photo oxidation, Conjugated.

\section{INTRODUCTION}

Since the discovery that PPV exhibited electroluminescence ${ }^{[1]}$ there have been many studies into the structure property relationship of conjugated polymers. As yet, one material that is stable in a device and emits in the elusive blue region with reasonable efficiencies has not been found. Many of these studies have been based on model oligomers using the basic repeating units of the extended polymers ${ }^{[2][3][4][5]}$ while others make slight variations on the polymers structure.

The variation of side chain composition and length has been studied extensively and these studied have found that despite the domination of MEH-PPV in the field, asymmetrical side chains like those of MEH-PPV increase the conjugation length thus red shifting the fluorescence. It has also been found that long symmetrical side chains increase emissive efficiency due to increased chain separation ${ }^{[6]}$. The position of the substitutions on the aromatic units was studied and it was found that placing alkyloxy groups on adjacent points caused a red shift in the spectra ${ }^{[7]}$. Addition of phenyl and cyano groups to the vinylene linkages has also been studied, and it has been found that substitution of the bulky phenylene increased the Stokes shift of the material so the fluorescence efficiency of the polymer is decreased ${ }^{[8]}$. The addition of electron withdrawing cyano groups is designed to reduce the conjugation length of the polymers and so blue shift their emission. However it is found that depending on the position of substitution their effect is mainly to red shift the fluorescence ${ }^{[5]}$. The cis to trans ratio of the polymers is also being studied and it has been found that increasing the cis isomer ratio increases the fluorescence efficiency of the polymer ${ }^{[9]}$. The linkage positions on the aromatic rings has been altered and it has been found that ortho ${ }^{[10]}$ and meta ${ }^{[11]}$ linkage blue shifts the emission moderately due to a reduction in the conjugation length. The ortho linkage was also found to provide a high quantum efficiency. Finally a couple of studies have been carried out which replace the phenyl units of the back bone with naphthyl units in varying arrangements and on the whole the addition of these units have blue shifted the UV and fluorescence spectra ${ }^{[10][12][13][14]}$

It was planned to incorporate the most promising structural properties into a homologous series of polymers and to study the different substituent's effects on their optical properties. Given its dominance in the field, the properties of all polymers should be judged on the properties of PPV but given its insolubility a derivative with alkyloxy side chains was used. Firstly a polymer with alkyloxy side chains on every second phenyl ring (PPV-OPV figure1) was employed as this structure will allow for direct comparison to the PPV derivative PmPV (figure 1) which has attracted much attention in the field due to its blue shifted photoluminescence emission and high fluorescence efficiency ${ }^{[15][16]}$. It is also of interest due to it interactions with carbon nanotubes which it solubilises leading to nanocomposites with interesting properties. [17][18] 


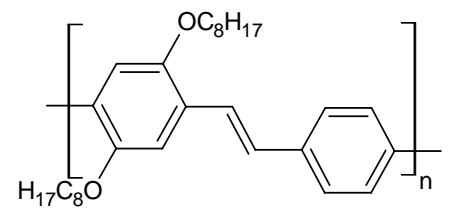

PPV-OPV

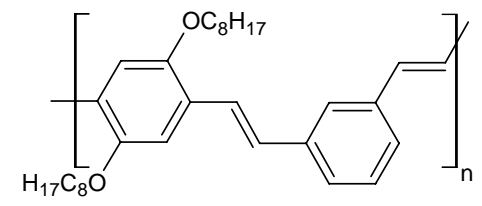

PmPV

Figure 1: Structures of Poly(-p-Phenyl vinylene-co-2,5-bis-octyloxy phenylvinylene) PPV-OPV and Poly(m-Phenyl vinylene-co-2,5-bis-octyloxy-p-phenylvinylene) PmPV

Secondly, a fully substituted derivative was synthesised (POPV) to enable the effects of alkyloxy substitution to be determined. The series was extended by replacing alternate substituted phenyl units with substituted naphthyl units (POPV-ONV figure 2) and finally all phenyl units were replaced to produce a fully conjugated naphthylene polymer (PONV, figure 2).

It is anticipated that comparisons of the spectra of PPV-OPV with POPV will demonstrate the effect of alkyloxy substitution on the electronic properties. Within the series the conjugated electronic structure of the polymeric backbone is maintained, and thus the effect of varying the backbone structure can be systematically elucidated. The meta linkage of PmPV is only partially conjugated and so will serve to demonstrate the importance of backbone conjugation on the optical properties of these groups of materials. The systematic study of these properties will generate guidelines for structure property relationships in these systems.

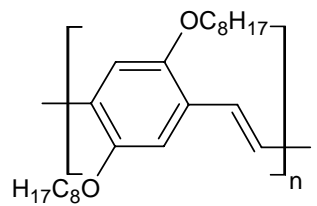

POPV

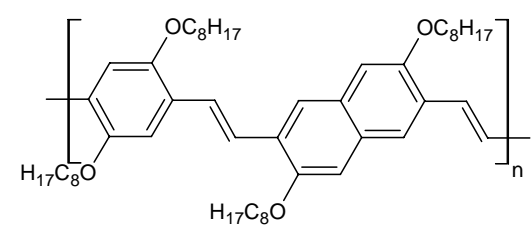

POPV-ONV

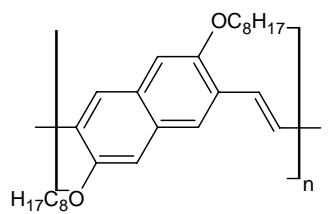

PONV

Figure 2: Structures of Poly (para-2,5-bis-(n-octyloxy)-phenyl vinylene) POPV, Poly(2,5-bis(n-octyloxy)-1,4phenylene vinylene-1,5-bis(n-octyloxy)-2,6-naphthylene vinylene) POPV-ONV and Poly(2,6-di-(n-octyloxy)1,5-NaphthyleneVinylene) PONV 


\section{EXPERIMENTAL}

\subsection{Synthesis}

Figure 3 shows the synthetic routes to the two starting materials, the aldehyde and the phosphonate ylide. The alkyloxy side chains are introduced during the synthsises of the aldehyde from the corresponding diol. The phosphonate ylide is synthesised by the Arbuzov reaction.

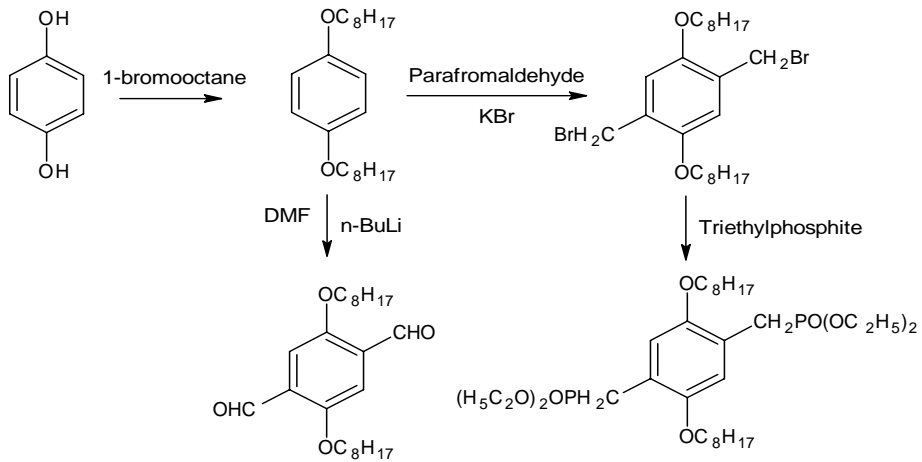

2
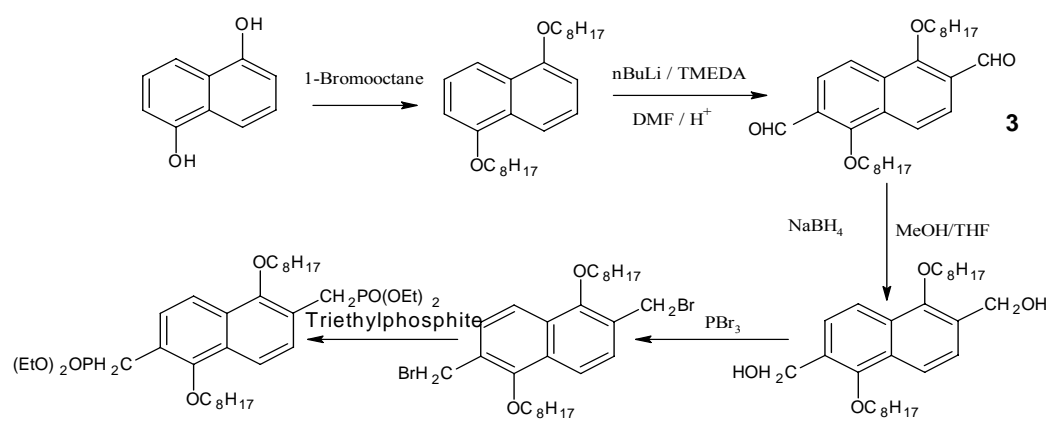

4

Figure 3: Synthetic routes to polymer starting materials

The polymerisation schemes are shown in figure 4. Soluble PPV derivatives with alkyloxy side chains have been synthesised by many different methods including the Gilich route ${ }^{[19]}$ the aryl/ethylene coupling via Heck and Suzuki reactons, ${ }^{[20]}$ and the McMurray ${ }^{[21]}$ and Wessling-Zimmermann route ${ }^{[22]}$. However polymers synthesised by these routes can contain structural defects due to incomplete elimination of precursor functional groups, crosslinking or other side reactions. $^{[23]}$ Both the Wittig ${ }^{[24]}$ and its variation the Horner-Emmons reactions ${ }^{[25]}$ produce polymers of well defined structure, and are suitable for preparing alternating copolymers. However while the Wittig reaction produces polymers with both cis and trans isomers about the vinyl bond it has been shown that the Horner route produces practically all trans bonds which will further simplify the structure. ${ }^{[26]}$ Further studies have shown that the Horner reaction carried out at $80{ }^{\circ} \mathrm{C}$ employing DMF as the solvent produced the longest chain polymers in the highest yields ${ }^{[27]}$. These conditions will be used for all polymerizations in this study. 


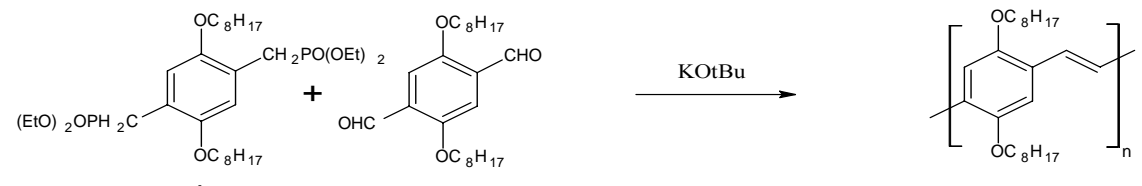

2<smiles>CCOc1cc(/C=C/c2cccc(/C=C(\C)CC)c2)c(OCC)c(C)c1OCCO</smiles>

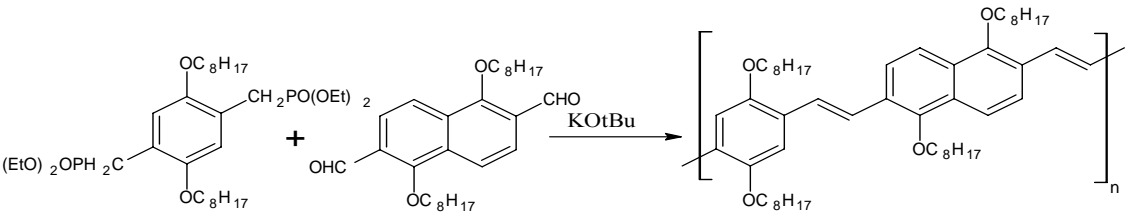

1

3

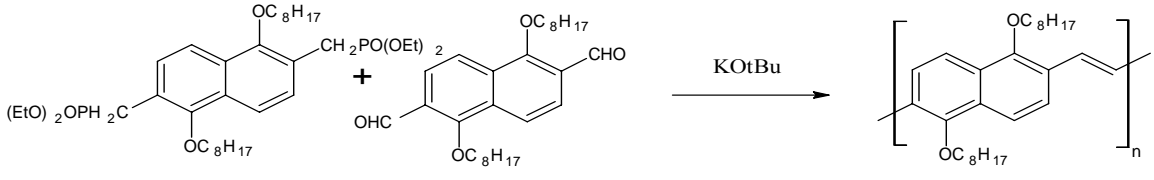

PONV

Figure 4: Polymerisation routes

All solvents and reagents were obtained from Sigma-Aldrich and used without further purification.

\section{1,4-Di-n-octyloxybenzene}

To DMSO (92 $\mathrm{cm}^{3}$, dried over $\left.\mathrm{MgSO}_{4}\right)$ powdered $\mathrm{KOH}(41.09 \mathrm{~g}, 0.73 \mathrm{~mol})$ was added. After stirring for $10 \mathrm{~min}, p$ hydroquinone ( $20.35 \mathrm{~g}, 0.18 \mathrm{~mol}$ ) was added, followed immediately by octylbromide $(71.08 \mathrm{~g}, 0.37 \mathrm{~mol})$. After stirring for $30 \mathrm{~min}$ the mixture was poured into water $\left(552 \mathrm{~cm}^{3}\right)$ and left to stand for $1.5 \mathrm{hr}$. The waxy product was collected by filtration and re-crystallised from $n$-heptane. After filtration and drying white flakes of 1,4-Di-n-octyloxybenzene (45.35 g, $73.84 \%$ ) were obtained.

Melting Range: $56-57^{\circ} \mathrm{C}$

${ }^{1} \mathrm{H}-\mathrm{NMR}\left(200 \mathrm{MHz}, \mathrm{CDCl}_{3}\right)[\mathrm{ppm}]: 6.82(\mathrm{~s}, 4 \mathrm{H}), 3.89(\mathrm{t}, 4 \mathrm{H}), 1.75$ (qui, 4H), $1.29-1.59(\mathrm{~m}, 20 \mathrm{H}), 0.88(\mathrm{t}, 6 \mathrm{H})$

${ }^{13} \mathrm{C}-\mathrm{NMR}\left(50 \mathrm{MHz}, \mathrm{CDCl}_{3}\right.$ ) [ppm]:153.15, 115.31, 68.59, 31.80, 29.37, 29.24, 26.04, 22.64, 14.09

Di-n-octyloxy-1,4-bis(bromomethyl)-benzene.

The reaction is very senative to impurities and therefore all flasks were soaked in $4 \mathrm{M} \mathrm{HCl}$ overnight

A mixture of 1,4-di-n-octyloxybenzene $(12.20 \mathrm{~g}, 37 \mathrm{mmol})$, paraformaldehyde $(15.76 \mathrm{~g}, 53 \mathrm{~mol})$ and $\mathrm{KBr}(23.20 \mathrm{~g}$ $, 0.20 \mathrm{~mol})$ was heated in glacial acetic acid $\left(200 \mathrm{~cm}^{3}\right)$ to $80^{\circ} \mathrm{C}$. A mixture of glacial acetic acid $\left(25 \mathrm{~cm}^{3}\right)$ and concentrated sulphuric acid $\left(20 \mathrm{~cm}^{3}\right)$ was added drop-wise over $0.5 \mathrm{hr}$. After stirring for an additional $5 \mathrm{hr}$. at $80^{\circ} \mathrm{C}$ the mixture was left to stand overnight. The crystals were filtered off, washed with water until the acetic acid smell disappeared and re-crystallised from n-heptane to give pale yellow fluffy needles (13.185 g, $73.1 \%)$.

Melting Range: $87-88^{\circ} \mathrm{C}$

${ }^{1} \mathrm{H}-\mathrm{NMR}\left(200 \mathrm{MHz}, \mathrm{CDCl}_{3}\right.$ ) [ppm]:6.85 (s, 2H), 4.52 (s, 4H), 3.98 (t, 4H), 1.81 (qui, 4H), 1.31-1.49 (m, 20H), 0.889 (t, $6 \mathrm{H})$

${ }^{13} \mathrm{C}-\mathrm{NMR}\left(50 \mathrm{MHz}, \mathrm{CDCl}_{3}\right)[\mathrm{ppm}]: 150.62,127.47,114.58,68.95,31.79,29.28,29.2,28.72,26.05,22.64,14.01$. 
2,5-Di-n-octyloxy-1,4-xylene-diethylphosphonate-ester Compound 1

Triethylphosphite $(9.05 \mathrm{~g}, 52.12 \mathrm{mmol})$ and 2,5-di-n-octyloxy-1,4-bis(bromomethyl)-benzene (13.00 g, $26.06 \mathrm{mmol})$ were heated to $150{ }^{\circ} \mathrm{C}$ for $4 \mathrm{hr}$. while the by-product ethylbromide was continuously removed by distillation. After filtration through cotton wool and re-crystallisation from petroleum ether, pale yellow crystals were obtained (10.01 $\mathrm{g}$, $71.4 \%)$.

Melting Range: $50-51^{\circ} \mathrm{C}$

${ }^{1} \mathrm{H}-\mathrm{NMR}\left(200 \mathrm{MHz}, \mathrm{CDCl}_{3}\right.$ ) [ppm]: 6.92 (s, 2H), 4.02 (qua, 8H), 3.92 (t, 4H), 3.28 (d, 4H) 1.77 (qui, 4H), 1.29-1.24 $(\mathrm{m}, 32 \mathrm{H}), 0.89(\mathrm{t}, 6 \mathrm{H})$

${ }^{13} \mathrm{C}-\mathrm{NMR}\left(50 \mathrm{MHz}, \mathrm{CDCl}_{3}\right)$ [ppm]: 150.25, 119.27, 114.75, 68.83, 61.70, 31.67, 29.26, 29.12, 27.47, 25.99, 24.69, $22.51,16.21,13.94$

\section{1,4-Bis(n-octyloxy)-2,5-phenyldialdehyde Compound 2}

(carried out under nitrogen)

A solution of 1,4-Di-n-octyloxybenzene (10.26 g, $30.6 \mathrm{mmol})$ and TMEDA $\left(24.0 \mathrm{~cm}^{3}, 159.9 \mathrm{mmol}\right)$ in diethyl ether (450 $\left.\mathrm{cm}^{3}\right)$ was cooled to $0{ }^{\circ} \mathrm{C}$ and bubbled with nitrogen for ten minutes. A $1.6 \mathrm{M}$ solution of $\mathrm{n}$-BuLi in hexane $\left(100 \mathrm{~cm}^{3}, 160\right.$ mmol) was added drop-wise over $30 \mathrm{~min}$. The mixture was stirred at $0^{\circ} \mathrm{C}$ for $1 \mathrm{hr}$ and was then slowly warmed to reflux. After being refluxed for $20 \mathrm{hr}$. the nitrogen was turned off and the resulting green solution was cooled to $0^{\circ} \mathrm{C}$ and $\mathrm{DMF}$ $\left(20 \mathrm{~cm}^{3}, 260 \mathrm{mmol}\right)$ was added drop-wise. The mixture was stirred at $0{ }^{\circ} \mathrm{C}$ for $2 \mathrm{hr}$. Then $4 \mathrm{M} \mathrm{HCl}\left(95 \mathrm{~cm}^{3}\right)$ was added slowly with vigorous stirring. The resulting two-phase system was stirred for an additional 30 min. The organic layer was separated, washed with $0.5 \mathrm{M} \mathrm{HCl}\left(150 \mathrm{~cm}^{3}\right)$, saturated $\mathrm{NaHCO}_{3}\left(150 \mathrm{~cm}^{3}\right)$ solution, brine $\left(150 \mathrm{~cm}^{3}\right)$ and then dried over $\mathrm{MgSO}_{4}$. The solution was concentrated under reduced pressure to give a brown solid. The crude product was filtered over a short column (silica gel, DCM : Hexane 1:4) and left to crystallise as yellow needles (4.114 g, 34.46 \%) Melting Range: $69-71^{\circ} \mathrm{C}$

${ }^{1} \mathrm{H}-\mathrm{NMR}\left(200 \mathrm{MHz}, \mathrm{CDCl}_{3}\right.$ ) [ppm]:10.52(s, 2H), 7.42 (d, 2H), 4.08 (t, 4H), 1.87 (qui, 4H), 1.47-1.31 (m, 20H), $0.89(\mathrm{t}, 6 \mathrm{H})$

${ }^{13} \mathrm{C}-\mathrm{NMR}\left(50 \mathrm{MHz}, \mathrm{CDCl}_{3}\right)$ [ppm]:189.33, 155.14, 129.17, 111.50, 69.14, 31.72 , 29.17, 28.98, 25.96, 22.59, 14.03

\section{1,5-Bis(n-octyloxy)-2,6-naphthalenedialdehyde Compound 3}

(carried out under nitrogen)

A solution of 1,5-dioctyloxynaphthalene $(11.76 \mathrm{~g}, 30.6 \mathrm{mmol})$ and TMEDA $\left(24.0 \mathrm{~cm}^{3}, 159.9 \mathrm{mmol}\right)$ in diethyl ether (450 $\left.\mathrm{cm}^{3}\right)$ was cooled to $0{ }^{\circ} \mathrm{C}$ and bubbled with nitrogen for ten minutes. A $1.6 \mathrm{M}$ solution of $\mathrm{n}$-BuLi in hexane $\left(100 \mathrm{~cm}^{3}, 160\right.$ mmol) was added drop-wise over 30 minutes. The mixture was stirred at $0{ }^{\circ} \mathrm{C}$ for $1 \mathrm{hr}$ and was then slowly warmed to reflux. After being refluxed for $20 \mathrm{hr}$. during which any loss of diethyl ether was replaced, the nitrogen was turned off and the resulting green solution was cooled to $0{ }^{\circ} \mathrm{C}$ and DMF $\left(20 \mathrm{~cm}^{3}, 260 \mathrm{mmol}\right)$ was added drop-wise. The mixture was stirred at $0{ }^{\circ} \mathrm{C}$ for $2 \mathrm{hr}$. Then $4 \mathrm{M} \mathrm{HCl}\left(95 \mathrm{~cm}^{3}\right)$ was added slowly with vigorous stirring. The resulting two-phase system was stirred for an additional 30 minutes. The organic layer was separated, washed with $0.5 \mathrm{M} \mathrm{HCl}\left(150 \mathrm{~cm}^{3}\right)$, saturated $\mathrm{NaHCO}_{3}\left(150 \mathrm{~cm}^{3}\right)$ solution, brine $\left(150 \mathrm{~cm}^{3}\right)$ and then dried over $\mathrm{MgSO}_{4}$. The solution was concentrated under reduced pressure to give a brown solid. The crude product was filtered over a short column (silica gel, DCM : Hexane $1: 4)$ and left to crystallise as a pale yellow solid $(5.339 \mathrm{~g}, 39.76 \%)$

Melting Range: $58-60.5^{\circ} \mathrm{C}$

${ }^{1} \mathrm{H}-\mathrm{NMR}\left(200 \mathrm{MHz}, \mathrm{CDCl}_{3}\right)$ [ppm]:10.499(s, 2H), 7.916 (d, 2H), 7.861 (d, 2H), 4.068 (t, 4H), 1.837 (qui, 4H), 1.464 (qui, 4H), $1.208(\mathrm{~m}, 16 \mathrm{H}), 0.804(\mathrm{t}, 6 \mathrm{H})$

${ }^{13} \mathrm{C}-\mathrm{NMR}\left(50 \mathrm{MHz}, \mathrm{CDCl}_{3}\right.$ ) [ppm]:189.443, 161.406, 132.975, 127.269, 123.437, 119.355, 79.345, 31.641, 30.093, $29.236,29.084,25.806,22.498,13.954$.

1,5-Bis-n-octyloxy-2,6-dihydroxymethylnaphthalene

1,5-bis-n-octyloxy-2,6-naphthalenedialdehyde $(3.33 \mathrm{~g})$, was dissolved in absolute ethanol $\left(400 \mathrm{~cm}^{3}\right)$ and THF $\left(60 \mathrm{~cm}^{3}\right)$. $\mathrm{NaBH}_{4}(3.7 \mathrm{~g})$ was added at room temperature. After stirring for $4 \mathrm{hr}$. the reaction mixture was concentrated under reduced pressure. The residue was taken up in dichloromethane $\left(1000 \mathrm{~cm}^{3}\right)$ and $3 \mathrm{M} \mathrm{HCl}\left(1000 \mathrm{~cm}^{3}\right)$ with vigorously stirring. The organic layer was separated and the aqueous layer was washed twice with dichloromethane $\left(500 \mathrm{~cm}^{3}\right)$. The combined organic layers were dried over $\mathrm{MgSO}_{4}$ and concentrated under reduced pressure to give a brownish solid (2.509 g $75.34 \%$ ).

Melting Range: $62-65^{\circ} \mathrm{C}$ 
${ }^{1} \mathrm{H}-\mathrm{NMR}\left(200 \mathrm{MHz}, \mathrm{CDCl}_{3}\right)[\mathrm{ppm}]: 7.651(\mathrm{~d}, 2 \mathrm{H}), 7.399$ (d, 2H), $4.761(\mathrm{t}, 2 \mathrm{H}), 4.013(\mathrm{t}, 4 \mathrm{H}), 2.448(\mathrm{~d}, 4 \mathrm{H}), 1.818$ (qui, $4 \mathrm{H}), 1.457$ (qui, $4 \mathrm{H}$ ), 1.226 (m, 16H,), 0.817 (t, 6H)

${ }^{13} \mathrm{C}-\mathrm{NMR}\left(50 \mathrm{MHz}, \mathrm{CDCl}_{3}\right.$ ) [ppm]:152.852, 129.262, 126.614, 118.427, 113.957, 75.412, 60.638, 31.805, 30.379, $29.241,26.221,26.061,22.632,14.088$.

1,5-Bis-n-octyloxy-2,6-dibromomethylnaphthalene

1,5-bis-n-octyloxy-2,6-dihydroxymethylnaphthalene $(1.02 \mathrm{~g})$ was dissolved in THF $\left(175 \mathrm{~cm}^{3}\right)$. Pyridine $\left(0.75 \mathrm{~cm}^{3}\right)$ was added and the reaction mixture was cooled to $0{ }^{\circ} \mathrm{C}$. Phosphorous tribromide $\left(2.5 \mathrm{~cm}^{3}\right)$ was added within 5 minutes giving a white precipitate. The reaction mixture was allowed to warm to room temperature, stirred for $20 \mathrm{hr}$ and then concentrated under reduced pressure. The residue was taken up in toluene $\left(150 \mathrm{~cm}^{3}\right)$ and water $\left(250 \mathrm{~cm}^{3}\right)$. The organic layer was separated and the water layer was extracted twice with toluene $\left(100 \mathrm{~cm}^{3}\right)$. The combined organic layers were dried with $\mathrm{MgSO}_{4}$ and concentrated under reduced pressure to give a brownish solid. The crude product was purified by column chromatography (silica gel, toluene) to give a white solid. (1.046 g, $81.35 \%$ ).

${ }^{1} \mathrm{H}-\mathrm{NMR}\left(200 \mathrm{MHz}, \mathrm{CDCl}_{3}\right.$ ) [ppm]:7.793 (d, 2H), 7.383 (d, 2H), 4.656 (s, 2H), 4.027 (t, 4H), 1.857 (qui, 4H), 1.489 (qui, 4H), 1.359, 1.250, (multi, 14H), $0.838(\mathrm{t}, 6 \mathrm{H})$

${ }^{13} \mathrm{C}-\mathrm{NMR}\left(50 \mathrm{MHz}, \mathrm{CDCl}_{3}\right)[\mathrm{ppm}]: 153.848,129.909,126.995,114.645,105.181,68.107,31.823,30.404,29.258$, 28.203, 26.238, 22.64914 .090

1,5-Bis-n-octyloxy-2,6-dimethylnaphthalene-bis-ethylphosphonate ester Compound 4

A mixture of 1,5-bis-n-octyloxy-2,6-dibromomethylnaphthalene $(0.9 \mathrm{~g})$ and triethylphosphite $(7.56 \mathrm{~g})$ was heated at 150 ${ }^{\circ} \mathrm{C}$ for $4 \mathrm{hr}$. while the by-product ethyl bromide was continuously removed by distillation. Any remaining solvent was removed by rotary evaporation. After leaving the viscous liquid overnight yellow low melting crystals formed in the flask.

This material is air sensitive and therefore was not isolated for characterisation.

Poly(-m-Phenyl vinylene-co-2,5-di-octyloxy-p-phenylvinylene) PmPV

A solution of 2,5-di-n-octyloxy-1,4-xylene-diethyl-phosphonate-ester $(4.000 \mathrm{~g})$ and isophthalaldehyde $(0.843 \mathrm{~g})$ in DMF $\left(20 \mathrm{~cm}^{3}\right)$ was heated to $80^{\circ} \mathrm{C}$. Potassium tert-butoxide $(2.118 \mathrm{~g})$ was added at once. The reaction mixture was left stirring at $80^{\circ} \mathrm{C}$ for additional $4 \mathrm{hr}$ and then poured into water $\left(150 \mathrm{~cm}^{3}\right)$. The resulting suspension was extracted three times with toluene $\left(30 \mathrm{~cm}^{3}\right)$. The organic layer was washed with water and dried over $\mathrm{MgSO}_{4}$. The solvent was then reduced by rotary evaporation and the product precipitated with methanol. Finally the product was filtered to give an orange solid $(2.399 \mathrm{~g} 85.3 \%)$

${ }^{1} \mathrm{H}-\mathrm{NMR}\left(200 \mathrm{MHz}, \mathrm{CDCl}_{3}\right)[\mathrm{ppm}]: 7.91,7.88,7.67,7.26,4.05,1.95,1.60,1.33,0.91$.

Poly [para-2,5-bis(n-octyloxy)-phenyl vinylene] POPV

A solution of 2,5-di-n-octyloxy-1,4-xylene-diethylphosphonate-ester (1.26 g, 2 mmol), 1,4-Bis(n-octyloxy)-2,5phenyldialdehyde $(0.78 \mathrm{~g}, 2 \mathrm{mmol})$ and DMF $\left(25 \mathrm{~cm}^{3}\right)$ was heated to $80^{\circ} \mathrm{C}$. Potassium tert-butoxide $(0.7 \mathrm{~g}, 5.5 \mathrm{mmol})$ was added at once. The reaction mixture was stirred at $80^{\circ} \mathrm{C}$ for an additional $4 \mathrm{hr}$ and then poured into water $\left(150 \mathrm{~cm}^{3}\right)$. The suspension thus formed was extracted four times with toluene $\left(30 \mathrm{~cm}^{3}\right)$. The organic layer was washed with water and dried over $\mathrm{MgSO}_{4}$. The solvent was then reduced by rotary evaporation and the product precipitated with methanol. Finally the product was Soxhlet extracted (methanol) for $24 \mathrm{hr} .(0.38 \mathrm{~g} 47.9 \%)$

${ }^{1} \mathrm{H}-\mathrm{NMR}\left(200 \mathrm{MHz}, \mathrm{CDCl}_{3}\right)[\mathrm{ppm}]: 7.44(2 \mathrm{H}), 7.26(2 \mathrm{H}), 4.04(4 \mathrm{H}), 1.84(4 \mathrm{H}), 1.54(4 \mathrm{H}) 1.29(16 \mathrm{H}), 0.875(6 \mathrm{H})$

${ }^{13} \mathrm{C}-\mathrm{NMR}\left(50 \mathrm{MHz}, \mathrm{CDCl}_{3}\right.$ ) [ppm]:151.10, 123.33, 69.50, 31.96, 29.45, 26.40, 22.75, 14.18.

Poly(2,5-bis(n-octyloxy)-1,4-phenylene vinylene-1,5-bis(n-octyloxy)-2,6-naphthylene vinylene) POPV-ONV

A solution of 1,5-bis(n-octyloxy)-2,6-naphthalenedialdehyde $(0.189$ g), 2,5-di-n-octyloxy-1,4-xylene-diethylphosphonate-ester $(0.250 \mathrm{~g})$ in DMF $\left(20 \mathrm{~cm}^{3}\right)$ was heated to $80^{\circ} \mathrm{C}$. Potassium tert-butoxide $(0.7 \mathrm{~g})$ was added at once. The reaction mixture was left stirring at $80^{\circ} \mathrm{C}$ for additional $4 \mathrm{hr}$ and then poured into water $\left(150 \mathrm{~cm}^{3}\right)$. The resulting suspension was extracted three times with toluene $\left(30 \mathrm{~cm}^{3}\right)$. The organic layer was washed with water and dried over $\mathrm{MgSO}_{4}$. The solvent was then reduced by rotary evaporation and the product precipitated with methanol. Finally the product was filtered to give an orange solid $(0.375 \mathrm{~g} 87.4 \%)$

Melting Point: $>300^{\circ} \mathrm{C}$

${ }^{1} \mathrm{H}-\mathrm{NMR}\left(200 \mathrm{MHz}, \mathrm{CDCl}_{3}\right)[\mathrm{ppm}]: 7.91,7.88,7.67,7.26,4.05,1.95,1.60,1.33,0.91$ 
Poly(2,6-bis(n-Octyloxy)-1,5-NaphthyleneVinylene) PONV

A solution of 1,5-bis(n-octyloxy)-2,6-naphthalenedialdehyde (0.66 g), 1,5-bis-n-octyloxy-2,6-dimethylnaphthalene-bisethylphosphonate ester $(1.104 \mathrm{~g})$ in DMF $\left(25 \mathrm{~cm}^{3}\right)$ was heated to $80^{\circ} \mathrm{C}$. Potassium tert-butoxide $(0.7 \mathrm{~g})$ was added at once. The reaction mixture was left stirring at $80^{\circ} \mathrm{C}$ for additional $4 \mathrm{hr}$ and then poured into water $\left(900 \mathrm{~cm}^{3}\right)$. The resulting suspension was extracted six times with toluene $\left(30 \mathrm{~cm}^{3}\right)$. The organic layer was washed with water until the aqueous layer was clear and dried over $\mathrm{MgSO}_{4}$. The solvent was then reduced by rotary evaporation and the product precipitated with methanol. Finally the product was filtered to give a brown solid $(0.0806 \mathrm{~g} 4.82 \%)$

Melting Point: $>350^{\circ} \mathrm{C}$

${ }^{1} \mathrm{H}-\mathrm{NMR}\left(200 \mathrm{MHz}, \mathrm{CDCl}_{3}\right)[\mathrm{ppm}]: 7.428,3.917,2.843,1.980,1.070,0.707$.

\subsection{Spectroscopy and GPC}

\section{UV-VIS}

$1 \times 10^{-5} \mathrm{M}$ solutions of the polymers were prepared in $\mathrm{CHCl}_{3}$ or toluene and spectra were recorded using a Perkin Elmer Lamda 900 UV/VIS/NIR Spectrometer. This spectrometer has a double-beam, double monochromator ratio recording system with tungsten-halogen and deuterium lamps as sources. The spectrometer has a range from 175 to $3300 \mathrm{~nm}$ with an accuracy of $0.08 \mathrm{~nm}$ in the uv-visible region. It has a photometric range of \pm 6 in absorbance.

\section{Fluorescence}

The fluorescence spectra of the above samples were then measured using a Perkin Elmer LS55B Luminescence spectrometer. The spectrum was recorded using a attenuated scan method which has a $1 \%$ attenuation setting The sample was excited at the $\lambda_{\max }$ measured above. The spectrometer is a computer controlled ratioing luminescence spectrometer with the capability of measuring fluorescence or phosphorescence. Excitation is provided by a pulsed Xenon discharge lamp, of pulse width at half peak height of $<10$ micro seconds and pulse power of $20 \mathrm{~kW}$. The source is monochromated using a Monk-Gillieson type monochrometer with a range of 200-800 nm. The excitation and emission slits can be varied from $2.5-15 \mathrm{~nm}$ in $0.1 \mathrm{~nm}$ increments. For these spectra they were set at $5 \mathrm{~nm}$.

\section{Gel Permeation Chromatrography (GPC)}

Polymer solutions were injected $(100 \mu \mathrm{l})$ into a THF stream with a flow rate of $1 \mathrm{ml} /$ minute. Polystyrene standards were used as calibration standards. The pump was a Waters $600 \mathrm{E}$ and the columns were $7.8 \times 300 \mathrm{~mm}$ styragel: HT3(500 to $30,000 \AA)$ HT5 (50,000 to 4,000,000 $\AA$ ) and HT6E (5,000-10,000,000 $\AA$ ). The pump employed was a Waters 410 differential spectrometer set a $260 \mathrm{~nm}$.

\section{RESULTS AND DISCUSSION}

Table 1 Characteristics of Polymers

\begin{tabular}{lccccccc}
\hline Polymer & $\begin{array}{c}\lambda_{\max } \mathrm{Abs} . / \\
\mathrm{nm}\end{array}$ & $\begin{array}{c}\lambda_{\max } \text { Em./ } \\
\mathrm{nm}\end{array}$ & $\begin{array}{c}\text { Stokes shift/ } \\
\mathrm{eV}\end{array}$ & $\mathrm{M}_{\mathrm{w}} \mathrm{g} / \mathrm{mol}$ & $\mathrm{M}_{\mathrm{n}} \mathrm{g} / \mathrm{mol}$ & $\mathrm{M}_{\mathrm{w}} / \mathrm{M}_{\mathrm{n}}$ & $\mathrm{N}_{\mathrm{av}}$ \\
\hline PPV-OPV & 458 & 521 & 0.33 & 24880 & 5000 & 4.97 & 11 \\
PmPV & 403 & 455 & 0.35 & 17200 & 6500 & 2.65 & 14 \\
POPV & 472 & 544 & 0.35 & 2530 & 1849 & 1.38 & 5 \\
POPV-ONV & 457 & 515 & 0.31 & 2960 & 1080 & 1.54 & 3 \\
PONV & 420 & 468 & 0.30 & 2300 & 1180 & 1.95 & 6 \\
\hline
\end{tabular}

\subsection{Spectroscopic Characterisation}

The physical property measurements for each polymer are listed in table 1. Gel permeation chromatography using polystyrene standards reveals that while similar synthetic routes and conditions were employed, polymers with alkyloxy side chains on every aromatic unit have much shorter chain lengths. This may be due to steric hindrance. The molecular weights of these polymers are not sufficient to produce good quality thin films which is important for device manufacture. However it has been shown that, in terms of electronic properties, changes caused by increasing the conjugated length saturate at ca. $10-20$ double bonds ${ }^{[28]}$ so the chain lengths are sufficient to represent extended $\pi$ systems for this study.

The Absorbance and Photoluminescence spectra of the polymers PPV-OPV and POPV were measured in toluene with the polymers being excited at their respective $\lambda_{\max }$.Abs (figure 5). The addition of alkyloxy side chains causes an electron donating effect which serves to decrease the bandgap between the HOMO and LUMO thus red shifting the absorption spectra. This effect is quite evident in the spectra. The vibronic structure seen in the PPV-OPV as a shoulder 
at $557 \mathrm{~nm}$ in the photoluminescence spectra is no longer present as we place alkyloxy side chains on every phenyl unit. The vibronic structure may be smeared due to increased rotation or alternatively, the main peak in the PPV-OPV emission spectrum may have been associated with the radiative decay of excited electrons associated with the non substituted phenyl ring with the shoulder due to the substituted phenyl ring. The spectrum of POPV only has one main emission as it has alkyloxy substitution on every ring giving the molecule greater symmetry and so a narrower emission. The red shift in the PL maximum of POPV is due to the electron-donating alkyloxy groups being added to the phenyl units causing an asymmetrical destabilization of the frontier orbitals ${ }^{[12]}$. The fluorescence intensity of the non substituted phenyl ring is greater than the substituted ring and the PPV-OPV scan was performed with different entrance and exit slit widths to decrease the intensity so both spectra could be displayed. From these spectra we calculate the band gap of PPV to be $2.74 \mathrm{eV}$ with a Stokes shift of $0.338 \mathrm{eV}$ while POPV has a band gap of $2.69 \mathrm{eV}$ with a Stokes shift of $0.419 \mathrm{eV}$. It is noted that the Stokes shift is larger for POPV suggesting that the substituted polymer loses more energy due to electron phonon coupling.

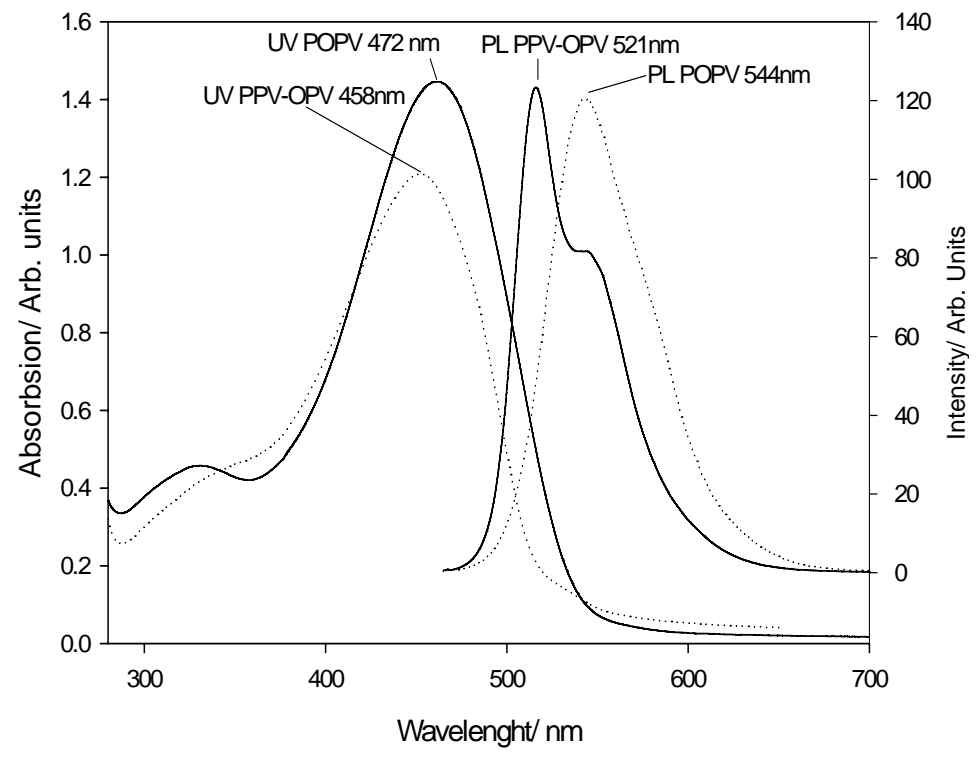

Figure 5 Absorption and Photoluminescence Spectra of PPV OPV and POPV

The UV and photoluminescence spectra of all the polymers in the series recorded as solutions in Chloroform are presented in figures 6 . As expected the spectrum of PmPV has the largest bathochromatic shift in the series. The change from a para linked phenyl in the PPV-OPV to a meta-linked phenyl in the PmPV significantly disrupts the conjugation along the polymer backbone with a concomitant blue shifting of both emission and absorption energies as shown in figure 6. It can also be clearly seen that as the phenyl unit is replaced with naphthyl units that the spectra show a bathochromatic shift. Conjugation length alone does not explain these results The naphthyl group also introduces a disruption in the conjugation due to its tendency to localise electrons. Therefore the meta linkage provides the largest blue shift closely followed by the PONV, POPV-ONV and lastly the POPV. Thus it can be seen that the introduction of the heavier electrophilic naphthyl units disrupts and hinders the formation of the conjugation along the back-bone and as such increases the energy of both emission and absorption. It is also noticeable that the meta linkage is far more efficient at breaking up the conjugation along the backbone than the naphthyl units. It is of interest to compare the Stokes shift of the polymers, as it relates to electron vibrational coupling and thus nonradiative decay, which competes with fluorescence. The rigid PONV structure has the smallest Stokes shift. The more flexible PPV-OPV and POPV have larger Stokes shifts, while the POPV-ONV is intermediate. The replacement of the phenyl units of the polymer backbone has led to a decrease in the Stokes shift and so an improvement in radiative efficiency is expected. Conversely the meta linkage of PmPV causes a large Stokes shift so it follows that while the spectra are blue shifted, the meta linkage does 
not improve fluorescence efficiency. While no attempt has been made to measure the quantum efficiency of the polymers, the large fluorescence peak coupled with the Stokes shift results, is an indication that the efficiency of PONV is greater than that of the other polymers. As a whole in the series it can be seen that as systematic changes in back-bone structure are made there is a well definable and systematic change in the electron-vibrational coupling mechanisms. The greater disorder introduced into the structure by the naphthalene units limits the delocalisation of $\pi$ electrons by Coulomb interaction and the corresponding excitons are easily localised onto a single monomer. ${ }^{[29]}$
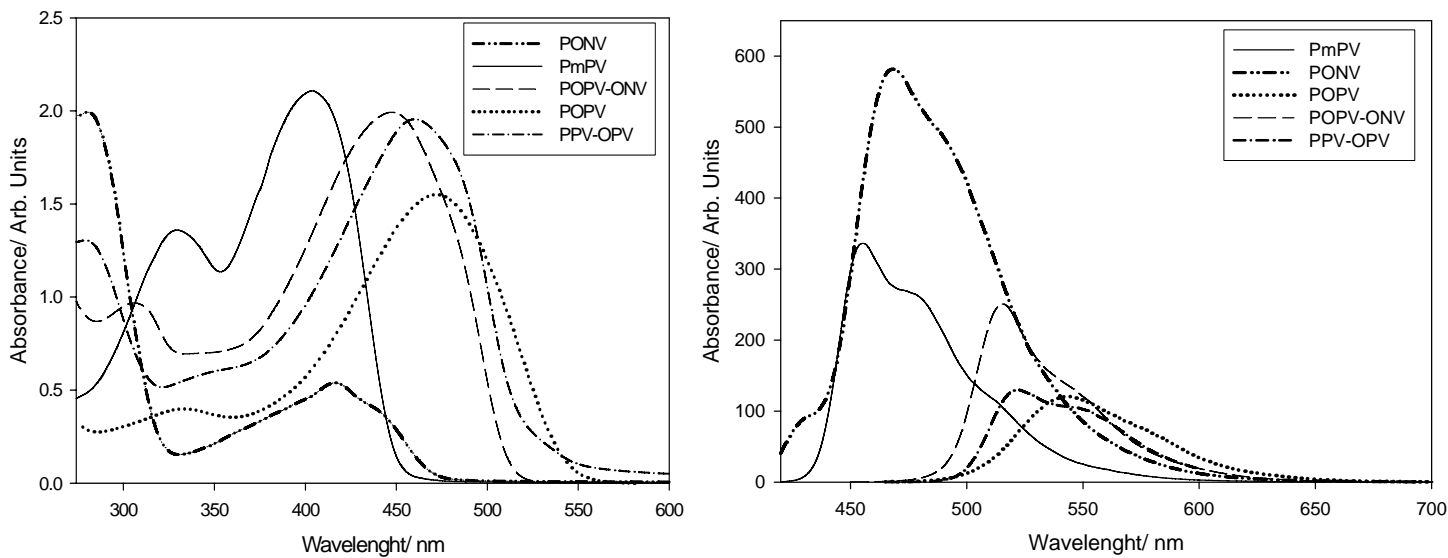

Figure 6: Absorption and Photoluminescence Spectra of all the polymers in the series in $\mathrm{CHCl}_{3}$

\subsection{Photo oxidation studies}

A $1 \times 10^{-5} \mathrm{M}$ solution of POPV in Chloroform was prepared and its absorbance spectrum was obtained. The solution was then irradiated with a UV lamp (main line $333 \mathrm{~nm}$ ) for six minutes. The $\lambda_{\max }$ of the main peak red shifted from $464 \mathrm{~nm}$ to $469 \mathrm{~nm}$ together with an increase in intensity the intensity of a lesser peak at $333 \mathrm{~nm}$ was also seen to increase. On irradiation for a further six minutes the peak is seen to blue shift to $466 \mathrm{~nm}$ with a decrease in the intensity of both the major and minor peaks. A new peak at $261 \mathrm{~nm}$ starts to appear. A further six scans were taken of the solution with six minutes of UV light irradiation between each scan. A trend of a blue shift in the major peak coupled with a decrease in intensity is observed together with an increase in the intensity of the $261 \mathrm{~nm}$ peak. Finally three more scans were obtained with twenty minutes of UV light irradiation between each scan to observe how the decay would progress. After a total of 108 minutes of UV light irradiation the $\lambda_{\max }$ of the major peak has shifted from its initial position of $464 \mathrm{~nm}$ to $422 \mathrm{~nm}$ and its intensity is ca. a third of its starting value The peak at $262 \mathrm{~nm}$ has increased dramatically and now has the highest intensity of any in the spectrum.

A proposed reason for the observations outlined above is photo-oxidation caused by dissolved oxygen in the solution and accelerated by the UV light. Degassing of the solutions was observed to slow down the affects but complete elimination of the UV-decay was not obtained.

NMR spectra of the POPV polymer in a $\mathrm{CDCl}_{3}$ solution was obtained prior to and after extended irradiation with UV light In the proton NMR the peaks due to octyloxy side chains are unchanged while those due to the vinylene units disappear completely. One single peak initially representing the two hydrogens on the phenyl ring remains however its integration represents five hydrogens. The $\mathrm{Ar}-\mathrm{O}-\mathrm{CH}_{2}-$ peak remained but is diminished. The ${ }^{13} \mathrm{C}$ NMRs were of poor quality due to solubility problems, and after the extended irradiation only peaks attributed to the octyloxy side chains are present. A study of the stability of a similar polymer MEH-PPV by M. Atreya et al. ${ }^{[30]}$ observed very similar behaviour in thin films and in xylene solutions of the polymer on exposure to UV light. The observed increase in the intensity of a peak at ca. $290 \mathrm{~nm}$ was attributed to the formation of a carbonyl group indicating photo-oxidation of the polymer. The study suggests that the blue shift and broadening of the spectra can be attributed to macromolecular chain scission leading to a broad distribution of conjugation lengths. PPV was observed to behave in a similar manner as POPV in 
Chloroform solution. It can be observed from figure 7 that the naphthalene polymer PONV does not degrade at the same rate as either PPV-OPV or POPV and while the same carbonyl peak does start to appear at $261 \mathrm{~nm}$ the rate of increase is much slower and the polymer seems much more stable to triplet oxygen attack than alkyloxy PPV derivatives which employ phenyl units in their back bone. Since degradation of organic LED's is a major draw back to their economic success it appears that while no attempt has been made to fabricate a PONV LEDs such a device may have a greater lifespan than that of other PPV derivatives.
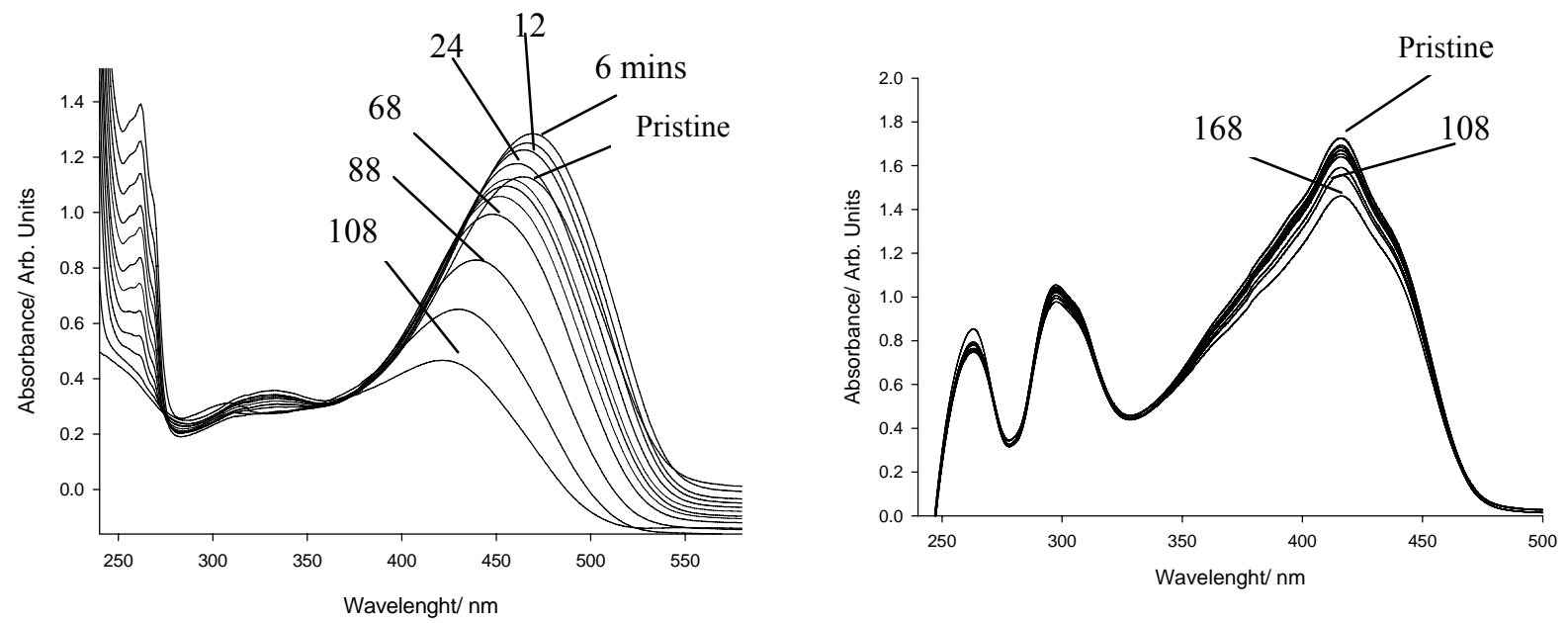

Figure 7 UV decay of POPV and PONV in chloroform

\section{CONCLUSION}

A series of PPV derivative polymers were prepared and their physical and optical properties were analysed. Introduction of fully alkyloxy substituted phenyl rings in POPV led to a red shift in the UV-vis and Fluorescence spectra as expected. The emission was also more regular with less vibronic structure compared to the emission of PPV-OPV due to the greater symmetry of the structure. The introduction of a meta linkage into the backbone served to disrupt the conjugation and so a blue shift in the spectra was observed. However the large Stokes shift indicates that fluorescence efficiency might not be improved. As naphthyl units replace the phenyl units of POPV in the structures POPV-ONV and PONV the absorbance and emission maxima are bathochromically shifted. This trend is attributed to the naphthyl units withholding electrons from overall conjugation. The photostability of the polymers POPV and PONV was monitored in solution and it was found that PONV has a greater stability towards photo-oxidation.

\section{ACKNOWLEDGEMENTS}

We would like to thank Dr. Stefanie Maier of Trinity College Dublin for samples of PPV-OPV. Also Dr. Manuel Reuther of Trinity College Dublin for assistance in running GPC analysis on the polymers.

Focas is funded under the Programme for Research in Third Level Institutions (PRTLI), administered by the HEA, of the National Development Plan 2000-2006 with assistance from the European Regional Development Fund

\section{REFERENCES} J.H. Burroughes, D.D.C. Bradley, A.R. Brown, R.N. Marks, K.D. Mackay, R.H. Friend, P.L. Burns, A.B. Holmes, Nature 347, (1990), 539.

2 O. Narwark, A. Gerhard, S. C. J. Meskers, S. Brocke, E. Thorn-Csanyi, H. Basser, Chemical Physics 294 (2003) 17 

Synthetic Metals 121, (2001), 1641. D. Oelkrug, J. Gierschner, H.-J Egelhaaf, L. Lüer, A. Tompert, K. Müllen, U. Stalmach, H. Meier. Synthetic Metals, 121 (2001) 1693

M Hanack, B. Behnisch, H. Häckl, P. Martinez-Ruiz, K.-H. Schweikart Thin Solid Films, 417, (2002,) 26. K.L. Brandon, D. D. C. Bradley, P. G. Bentley and D. A. Dunmur Synthetic Metals, 91, (1997), 305.

B.S. Chuah, F. Cacialli, J.E. Davies, N. Feeder, R.H. Friend, A.B.Holmes, E.A. Marseglia, S.C. Moratti, J.-L. BreÂdas, D.A. dos Santos,Mater. Res. Soc. Symp. Proc. 488, (1998), 87. S Maier, A. Dury, A. P. Davey, H.J.Byrne, W. J. Blau. Synthetic Metals, 119, (2001), 85.

D. O'Brien, A. Bleyer, D. G. Lidzey, and D. D. C. Bradley T. Tsutsui,. J. Appl. Phys. 82, (1997) 2662.

S. Maier,. A. Dury, A. P. Davey, H.J.Byrne, W. J. Blau. Synthetic Metals, 101, (1999) 31, B. Xu, J. Zhang, Y. Pan, and Z. Peng. Synthetic Metals, 107, (1999) 47,

M Hanack, J. L. Segura, and H. Spreitzer, Advanced materials. 8, (1996) 8.

B Behnisch, P. Mariinez-Ruiz, K-H Schweikart, M Hanack, Eur. J. Org. Chem. (2000) 2541.

S.E. Dottinger, M. Hohloch, J. L. Segura, E. Steinhuber, M. Hanack, A. Tompert, and P. Oelkrug, Advanced materials, 9 ,(1997), 3, 233-236

15. Y.Pang, J.li, B. Hu, F.E. Karasz Macromolecules 32 (1999) 3946

16 M. Yan, L. J. Rothberg, E. W. Kwock, and T. M. Miller. Phy. Rev. Lett. 75, (1995), 1992

17 S. A. Curran, P. A. Ajayan, W. J. Blau, D. C. Carroll, J. N. Coleman, A. B. Dalton, A. P. Davey, A. Drury, B. McCarthy, S. Maier and A. strevens, Advanced materials, 10, (1998), 1091-1093.

18 . J. N. Coleman, A. B. Dalton, S. Curran, A. Rubio, A. Davey, A. Drury B. McCarthy, B. Lahr, P. Ajayan, S. Roth, R. Barklie, W. J. Blau Advanced materials, 12, (2000), 213.

19 H. G. Gilich, W. L. Wheelwright, J Polym. Sci. part A: Polym. Chem., (1996), 4, 1337.

20 F. Koch, W. heitz, Macromol. Chem. 198 (1997) 1531

$21 \quad$ M. Rrhan and A. D. schluetter, Macromol. Rapid Commun.(1990) 375.

22 R. A. Wessling, .J. Polym. Symp. (1986), 72, 55

23 S. Pfeiffer, H..-H. Hörhold, Synthetic Metals. 101 (1999) 109

24 G. Drefahl, R. Kuehmstedt, H. Oswald, H. -H. Hörhold Macromol. Chem. (1970), 131, 89

H. -H. Hörhold, J. Opfermann, Makromol. Chem.. 131 (1970) 105

H. Rost, S. Pfeiffer, A Teuschel, H..-H. Hörhold Synthetic Metals. 84 (1997) 269

A. Dury, S. Maier, M. Rüther W. J. Blau, J. mater. Chem., 13, (2003), 485

A. Dury, S. Maier, A. P. Davey, A. B. Dalton, J. N. Coleman, H.J.Byrne, W. J. Blau Synthetic Metals 119 (2001) 151

H. J. Byrne, W. Blau, R. Giesa and R.C. Schulz, Chem. Phys. Lett., 167, (1990), 484-489

A. J. Heeger J. Phy. Chem. B 10536 (2001) 8475

M. Atreya, S. Li, E. T. Kang, K. G. Neoh, Z. H. Ma, K. L. Tan, W. Huang. Poly. Degr. And Stabiltity, 65, (1999), 287-296. 